\title{
Historical Lyonaise brace treatment for adolescent hyperkyphosis. Results of 272 cases reviewed 2 years minimum after removal of the brace
}

\author{
Jean Claude de Mauroy*, Pierre Vallèse, Paule Fender, Cyril Lecante \\ From 7th International Conference on Conservative Management of Spinal Deformities \\ Montreal, Canada. 20-22 May 2010
}

\section{Introduction}

The conservative orthopaedic treatment of hyperkyphosis is less classical than the scoliosis one, because Hyperkyphosis does not affect the respiratory function, and it is more difficult to define normality. The consequences of hyperkyphosis are mainly pain and aesthetic. In English literature very few homogeneous series of results are published. Lowe [1] in a review of the current literature using evidence-based medicine, concludes that when recognized early in adolescence with progressive kyphosis, bracing treatment will usually result in modest correction of the deformity. Sachs [2] analyzing the results of 274 patients concludes that the Milwaukee brace is usually an effective method of treatment for patients who have Scheuermann kyphosis; however, four of fourteen patients who had an initial kyphosis of more than 74 degrees required a spinal fusion. Weiss [3] analyzes the use of transverse correction forces instead of distraction forces with a 3 points brace in 56 patients. In Lyon, we use since 60 years, an historical protocol consisting of: plaster cast reduction, plexidur 5 points brace and specific exercises. Currently, this treatment is performed in day hospital.

\section{Material and methods}

272 patients (142 boys and 130 girls) with an average age of 136 months were treated from 1987 to 2005 and reviewed 2 years after removal of the brace, even if the compliance of bracing was not good. The diagnosis was Scheuermann in 119 cases and idiopathic in 153 cases.

\footnotetext{
Clinique du Parc, Lyon, France

Full list of author information is available at the end of the article
}

We have 10 cases of Thoracolumbar pattern. Patients were evaluated either by clinical and radiological examination. Since 1998 an automatic update of a specific spreadsheet is performed by the secretary during the medical control. All data were analyzed by SPSS 18 IBM software.

\section{Results}

The average Stagnara angle at the beginning of the treatment was $59.45^{\circ}\left(+-8^{\circ}\right)$. The average percentage of in-cast correction was $46 \%$ (from $6^{\circ}$ to $49^{\circ}$ ). If we consider that the norm value of kyphosis is $37^{\circ}$, we have an over correction in plaster cast of $122 \%$. There was no correlation between the percentage of in-brace correction and the age of the patient, but a significant correlation between the percentage of in-cast correction and the results of the treatment (Pearson $=0.49$ ). 2 years after the end of the treatment, the average Stagnara angle was $40.84^{\circ}\left(+-8^{\circ}\right)$ (from $-7^{\circ}$ to $\left.47^{\circ}\right)$. The average percentage of correction by the treatment considering the norm value of $37^{\circ}$ is $91 \%$. Only 3 patients demonstrated progression of the kyphosis. Boys are a little more rigid with an average percentage correction of $84 \%$. With Scheuermann the average percentage correction is $77 \%$. We also focus on the 10 cases with a thoracolumbar pattern with an average percentage correction of $55 \%$ (norm value kyphosis $0^{\circ}$ ). Figure 1

\section{Discussion}

The treatment should be initiated after the curvature exceeds 55 in a growing adolescent, especially for a boy with thoracic Scheuermann. Our results are worse for the thoracolumbar pattern which may predict chronic 


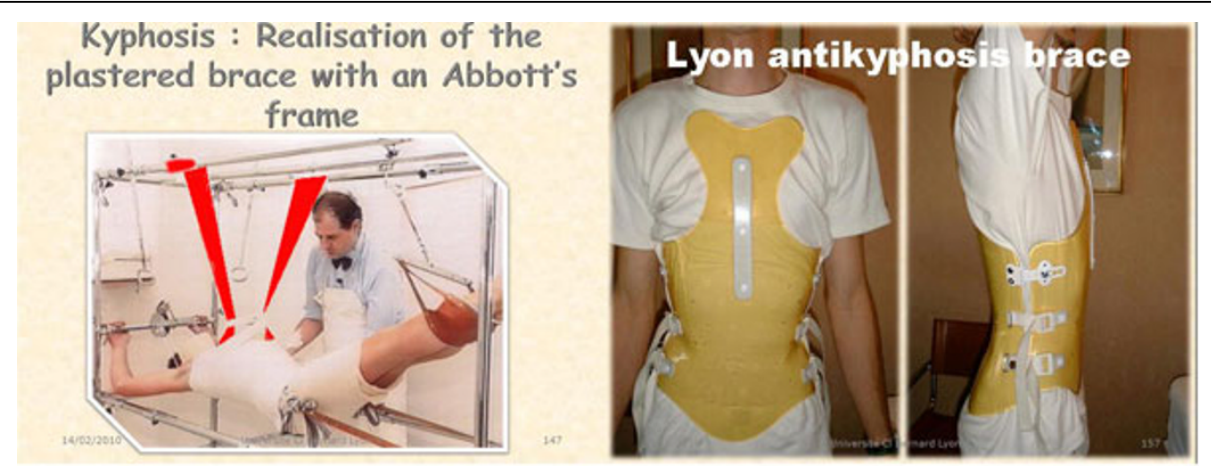

Figure 1

low back pain in adulthood with reduced quality of life of the patients and high costs with respect to medical care and occupational sickness leave. The treatment should be initiated after the thoracolumbar curvature exceeds $25^{\circ}$

\section{Conclusion}

Conservative treatment of hyperkyphosis in international literature is generally regarded as an effective treatment approach. Physiotherapy and bracing are the first-line treatments for this condition. The results of the Lyonaise management of kyphosis were very satisfactory in most patients.

Published: 10 September 2010

\section{References}

1. Lowe TG, Line BG: Evidence based medicine: analysis of Scheuermann kyphosis. Spine 2007, 32(19 Suppl):S115-119.

2. Sachs B, Bradford D, Winter R, Lonstein J, Moe J, Willson S: Scheuermann kyphosis. Follow-up of Milwaukee-brace treatment. J Bone Joint Surg Am. 1987, 69(1):50-57.

3. Weiss HR, Turnbull D, Bohr S: Brace treatment for patients with Scheuermann's disease - a review of the literature and first experiences with a new brace design. Scoliosis. 2009, 4:22.

\section{Submit your next manuscript to BioMed Central} and take full advantage of:

- Convenient online submission

- Thorough peer review

- No space constraints or color figure charges

- Immediate publication on acceptance

- Inclusion in PubMed, CAS, Scopus and Google Scholar

- Research which is freely available for redistribution 